\title{
Ovarian development in Cosmopolites sordidus Germar (Coleoptera: Curculionidae)
}

\author{
Richard P. Uzakah* \\ Department of Crop Protection and Environmental Biology, University of Ibadan, Nigeria
}

\begin{abstract}
This study was undertaken to determine the ovarian development of banana weevils. Results indicated that female banana weevils have a meroistic and telotrophic ovariole. Four (4) stages of ovarian development were observed. Newly emerged females belonged to stage I, characterized by virtual absence of oocytes in female germarium; while fully mature adult females belonged to stage IV, characterized by the presence of mature, chorionated eggs in female calyces. The intermediate stages II and III were characterized by presence of small, undeveloped oocytes, and presence of developed but non-chorionated oocytes in the vitellarium of female ovarioles, respectively. The preoviposition period in this insect was found to range between 27 and 41 DAE and egg-loads in calyces ranged from 2 to 11. All females at ovarian stage IV (i.e. ages 25 DAE and above) were found to have mated, and were ready for ovulation and oviposition. Monitoring the reproductive phenology of crop pests may be helpful for predicting (forecasting) potential outbreaks. it could also aptly guide the timing of control options, and also aid varietal screening works. Field samplings that result in heavy female populations and with predominant numbers at final stages of ovarian development, may be a danger signal that should trigger instant interventions.
\end{abstract}

Keywords: meroistic, telotrophic ovariole, ovarian development, pre-oviposition period, reproductive phenology

\section{Introduction}

The banana weevil, Cosmopolites sordidus Germar (Coleoptera: Curculionidae) is a major insect pest of bananas and plantains the world-over; causing considerable reductions in yearly productions of the crop globally [1], [2], [3]. The pest attacks all species of Musa and no cultivar is known to have a total resistance to it; although certain cultivars are now known to be more susceptible to the borer than others [3], [4], [5]. At present, no single control strategy provides effective control [5], and so integrated approaches involving pseudostem trapping, crop hygiene, careful varietal selections, pheromone trapping, poison baiting and use of properly selected insecticides are often adopted in controlling this pest.

For the development of novel control, knowledge of various facets of pest biology, ecology and behaviour is absolutely essential [6], [7]. Also, according to [8], thorough understanding of an insect's phenology allows for increased precision in the implementation of management techniques. The present study was therefore, aimed at investigating $C$. sordidus' ovariole type, ovarian development and pre-oviposition period with a view to help shed some light on vital aspects of the weevil's reproductive structure and phenology. It is hoped that the knowledge gained from this would help to reveal the reproductive status of field-females captured from surveys and traps, since such information is known to have a direct relationship with the damaging potential of pests [9]. Heavy female catches with significant proportions also being at late or final stages of ovarian development, will soon give rise to high field infestations and so should necessitate instant control measures, such as intensive trapping or even chemical control.

\subsection{Reproductive structure (Studies on Ovariole type)}

\section{Materials and methods}

Longitudinal sections of ovarioles of dissected adult females were passed through several histological processes of fixing in Boine's solution for 48 hours, washing-off excess fixatives and dehydrating the tissues in ascending alcohol grades of 30\%, 50\%,70\%, 90\% and absolute alcohol; and clearing in chloroform. Tissues were then infiltrated in molten paraffin wax and kept in an oven maintained at $56^{\circ} \mathrm{C}$ for $5 \mathrm{hrs}$ (renewing the paraffin wax at intervals of 1,2 and a further 2 hours, respectively). Tissues were thereafter embedded in molten paraffin wax and sectioned using Jung rotary microtome at six micron $(6 \mu)$ thickness. Sectioned tissues were mounted on microscope slides, stained with haematoxylin and counterstained with Eosin. Stained sections were finally examined under the compound microscope (Leitz Laborlux K) in order to determine the ovariole type of this pest. 


\subsection{Reproductive phenology (or Ovarian development studies)}

Fifty day-old females were placed singly in $130 \mathrm{ml}$ plastic tubes and to each was added two sexually mature (field collected) males. Pieces of pseudostems were introduced into the tubes as food, and these were renewed weekly to ensure that the weevils constantly remained in good condition. Tubes were properly labelled with dates of pairing and kept in an incubator maintained at $25 \pm 2{ }^{\circ} \mathrm{C}$ and r.h. of between $60-80 \%$.

At regular intervals of 2 days, two tubes were randomly selected and the females in such tubes dissected to assess:

- Presence or absence of oocytes in the ovaries

- State of development of the oocytes

- Presence or absence of mature or chorionated eggs in the calyx

These experiments were repeated at four different times. The data obtained at the end were then analyzed according to age of females and developmental stage of the ovaries. Records of insemination for all the dissected females were also kept in order to ascertain the relationship between insemination and the ovarian development of the insect.

\subsection{Preoviposition period}

Ten day-old females were paired singly with field collected, sexually mature males $(1: 1)$ in $130 \mathrm{ml}$ plastic tubes that contained pieces of pseudostems as food for the weevils. These tubes were kept in same laboratory conditions as outlined above, and food contained in these tubes also renewed every week. At two day intervals, two tubes were randomly selected and the pseudostems (plus the tubes) thoroughly examined for the presence of eggs. Females observed to have laid eggs were dissected immediately and records were kept on the number of eggs still found within them. This was done in order to determine whether females usually waited to mature or accumulate a full complement of eggs before oviposition commenced, or whether they oviposited as soon as eggs were present in the calyx.

\subsection{Reproductive histology}

\section{Results}

The examination of longitudinal sections of the female ovarioles did not reveal any nutritive cords at the connection between germarium and the oocytes. The concentrations of nurse cells (trophocytes) observed in the germarium (Fig. 1), is an arrangement typical of telotrophic type of ovariole.

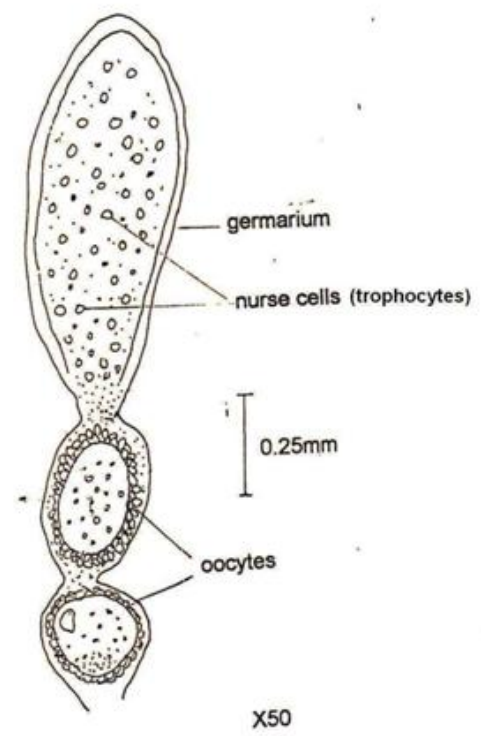

Fig. 1 A free-hand drawing of the longitudinal section of the banana weevil, C. sordidus ovarioles

\subsection{Reproductive phenology (Ovarian development)}

From the several data generated, it was possible to broadly categorize the entire ovarian development process of this insect into four (4) distinct stages (Plate 1; Fig. 2 below):

Stage I was characterized by virtual absence of oocytes in the vitellarium of ovarioles. (Female ages ranged between $1-16$ DAE, $n=84$ ) (Plate $1[\mathrm{I}]$ and Fig. 2a)

Stage II showed the presence of small, undeveloped oocytes in the vitellarium (females $11-28$ DAE, $\mathrm{n}=29$ ) (Plate 1 [II] and Fig. 2b) 
Stage IIIwas characterized by the presence of developed (but non-chorionated) oocytes in the vitellarium (females $24-58$ DAE, $\mathrm{n}=21$ ) (Plate 1[III], and Fig. 2c)

Stage IV showed the presence of mature, chorionated eggs (usually in the calyx of the females) (females 25 DAE and above, $\mathrm{n}=27$ ) (Plate $1[\mathrm{IV}]$ and Fig.2d)
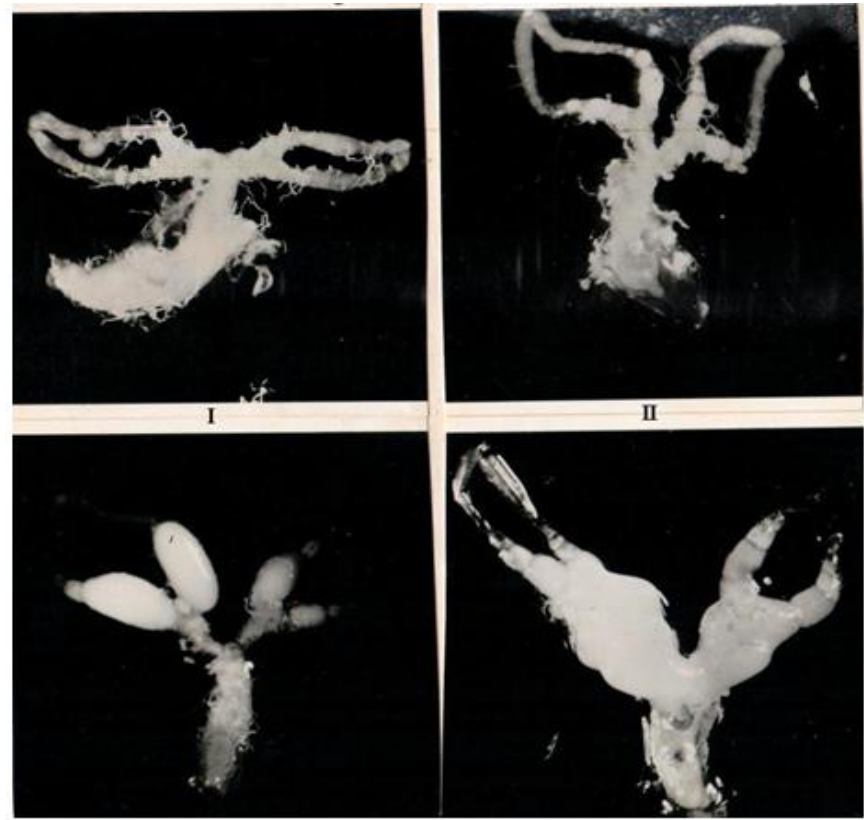

III

IV

Plate 1: A photomicrograph showing various stages (I - IV) of the ovarian development of C. sordidus

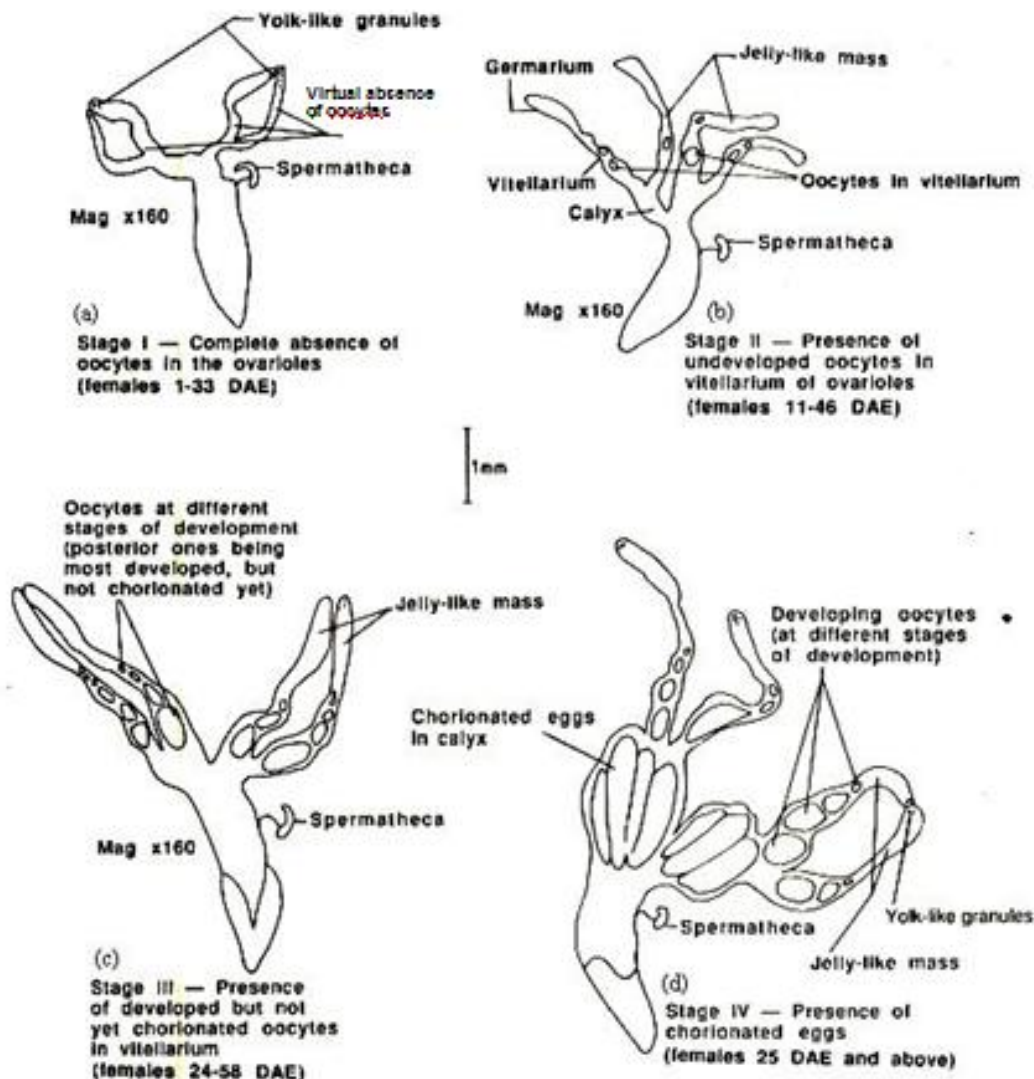

Fig. 2(a-d): A free hand drawing of the various stages (I - IV) of the ovarian development of the banana weevil, $C$. sordidus 


\subsection{Preoviposition period}

Table 1 reveals that the earliest record of oviposition by a mated female (preoviposition period) in this study was 27 DAE (range 27 - 41 DAE). No eggs were laid prior to this age. The dissections performed on these females following their first oviposition, showed diverse number of eggs in their calyces (range $2-11$ ).

Table 1: Preoviposition periods of different females of banana weevils under laboratory conditions, with records of number of eggs laid and retained in the calyx

\begin{tabular}{|cccc|}
\hline Serial No. & $\begin{array}{c}\text { Preoviposition period } \\
\text { (DAE*) }\end{array}$ & No. of eggs laid & $\begin{array}{c}\text { No. of eggs } \\
\text { retained in calyx }\end{array}$ \\
\hline 1 & 27 & 1 & 6 \\
2 & 29 & 1 & 5 \\
3 & 35 & 1 & 11 \\
4 & 41 & 1 & 2 \\
\hline
\end{tabular}

* Days after emergence

\section{Discussion}

The histological studies on longitudinal sections of $C$. sordidus revealed a concentration of nurse cells (trophocytes) in the germarium of female ovarioles, suggesting a meroistic and telotrophic type ovariole for this weevil; since in the panoistic, nurse cells are completely absent, but are found alternating with oocytes in the polytrophic. Nutritive cords which are specific to this type of ovariole could not be detected in this study. [10] reported that nutritive cords are very small and inconspicuous in Coleoptera, and hence often got overlooked. Nurse cells, according to [11] and [12], are usually more conspicuous in the Hemiptera. [13] however, reported that all Polyphaga Coleoptera have telotrophic ovarioles. A claim that is also supported by [14], that telotrophic ovarioles are histologically and ultrastructurally more complex than polytrophic ovarioles, and that electron microscope (EM) studies now reveal most Polyphaga Coleoptera as having telotrophic ovarioles. No EM works were done in this study. Four (4) distinct stages were observed in the ovarian development of this insect. Newly emerged females (i.e. females ranging from ages 1 - 16 DAE) belonged to the first stage (or stage I) and were characterized by the virtual absence of oocytes in their ovarioles, while the last developmental stage (i.e. stage IV) was associated with the presence of fully mature, chorionated eggs in the lateral oviducts and calyces of females (of ages $25 \mathrm{DAE}$ and above). The intermediate stages were represented with first appearance or emergence of undeveloped oocytes in the vitellarium of ovarioles (stage II; females $11-28$ DAE); and the presence of developed but non-chorionated eggs in the vitellarium (stage III; females 24 - 58 DAE) respectively. Majority of the females (72\%) at 21 DAE (i.e. age at which the females became sexually mature) belonged to Stages II and III. Not all females at 25 DAE and above were necessarily mated or at stage IV, but all females at Stage IV (irrespective of age) were mated. Their calyces were filled with mature eggs, ready for ovulation and subsequent oviposition.

The findings made in this study agreed with [12] account and diagrammatic representation of a 4-stage ovarian development in the Argentine stem weevil, Listronotus bonariensis (Kuschel) (Coleoptera : Curculionidae), but could not corroborate his claim of 8 stages of oocyte development in the weevil. [15] worked on the sweet clover weevil, Sitona cylindricollis Fabricollis (Coleoptera: Curculionidae) confirmed that female reproductive systems can be at different developmental stages at different times or seasons of the year. According to him, reproductive systems of female $S$. cylindricollis are undeveloped and unproductive prior to hibernation; but that overwintered females showed fully developed and productive reproductive systems. [16] revealed that maturation of ovaries in female insects are normally correlated with age until sexual maturity is reached. Correlations of ovarian development with female age are well established in insects [17]. [18] worked on the ladybird beetle Propylea dissecta (Coleoptera : Coccinellidae) and stated that mating accelerated ovarian development, and that increase in age led to increase in number of follicles, ovarian width, number of mature eggs and egg loads.

The pre-oviposition period of $C$. sordidus was in this study found to range between 27 and 41 DAE. Dissections of females that had just oviposited revealed a range of 2 to 11 chorionated eggs in the calyces of the females. It could not be confirmed if the females waited to have a full complement of eggs before ovipositions occurred, because of the diverse egg numbers found in the calyces of those ovipositing for the first time.The findings made in this study may be useful in predicting pending outbreaks (or pest-outbreak forecasting) for $C$. sordidus, and may also aptly guide proper timing of control options for the pest. For instance, any field survey that yields high female populations which are also predominantly at ovarian stage IV, may mean a danger signal that should trigger immediate interventions (e.g. mass trapping or even chemical control) to prevent possible outbreaks. [2] reported that capturing unmated and fertile female $C$. sordidus could play a significant role in slowing down the pest's population build-up. Other benefits may be in varietal screening works as susceptible cultivars would readily support rapid pest growth and developments, whilst resistant varieties lead to possible impairments and arrested developments, such as delays in oocyte emergence, oocyte maturation, and prolonged pre-oviposition periods. 


\section{Conclusion}

The banana weevil, C. sordidus possesses a meroistic and telotrophic ovariole; and there are four (4) stages in the pest's ovarian development. Newly emerged females, and young female adults belong to the initial stages I and II respectively; while older females generally fall into the later stages III and IV (with stage IV being typical of fully mature and ovipositing, or ready-to-oviposit female adults). The pre-oviposition period ranges between 27 and 41 DAE. Field samplings resulting in heavy female populations and predominated with late stages of ovarian development should be a danger signal for immediate intervention.

\section{Acknowledgements}

This study was part of the author's PhD work and was funded by the Royal Norwegian Ministry of Research Cooperation and Development (NORAD). It was conducted at the International Centre of Insect Physiology and Ecology (ICIPE) in Nairobi, using the facilities of the Behavioural and Chemical Ecology Research Unit. The useful contributions of all my supervisors and colleagues are highly appreciated.

\section{References}

[1]. H.E Ostmark (1974). Economic insect pests of bananas. Annual Review of Entomology 19: 161 - 176

[2]. W. Tinzaara, C.S. Gold, M. Dicke, A. Van Huis and P.E. Ragama (2011). Effect of age, female mating status and density on the banana weevil response to aggregation pheromone. African Crop Science Journal 19 (2): 105-116

[3]. B.N. Viswanath (1981). Development of Cosmopolites sordidus (Coleoptera: Curculionidae) on banana varieties in South India. Colemania 1(1): 57-58

[4]. A.L.M. Mesquita, E.J. Alves and R.C. Caldas (1984). Resistance of banana cultivars to Cosmopolites sordidus (Germar, 1824). Fruits 39 (4): 254257

[5]. C.S. Gold, J.E. Pena and E.B. Karamura (2001). Biology and integrated pest management for the banana weevil Cosmopolites sordidus (Germar) Coleoptera: Curculionidae). Integrated Pest Management Reviews 6: 79 - 155

[6]. D.G. Bottrell (1979). Integrated Pest Management. Council on Environmental Quality. U.S. Government Printing Office, Washington, D.C. $120 \mathrm{pp}$

[7]. R. Kumar (1984). Insect Pest Control with special reference to African agriculture. Edward Arnold (Publishers) Limited, London. $298 \mathrm{pp}$

[8]. G.M Barker, R.A Prestidge and R.P. Pottinger (1988). Reproductive phenology of Listronotus bonariensis (Kuschel) (Coleoptera: Curculionidae) in Northern New Zealand. Bulletin of Entomological Research 78: 659-668

[9]. V.A. Abraham, J.R. Faleiro, M.A. Al-Shuibi and S. Al Abdan (2001). Status of pheromone trap captured red palm weevils from date gardensin Saudi Arabia. Journal of Tropical Agriculture 39: 197 - 199

[10]. P.F. Bonhag (1958). Ovarian structure and vitellogenesis in insects. Annual Review of Entomology 3: 137-160

[11]. H.M. Chu, D.M. Norris and K.D.P. Rao (1982). Sorbic acid-induced differences in the ultrastructural development of oocytes in the microbially ectosymbiotic female of Xyleborous ferrugineus (Fabr.) (Coleoptera: Scotylidae). Journal of Morphology 173: $313-324$

[12]. G.M. Barker (1989). Functional anatomy of the reproductive system of Listronotus bonariensis (Kuschel). New Zealand Entomologist 12: 34-42

[13]. R.F. Chapman (1971). The Insects: Structure and Function. London, English Universities Press

[14]. E. Huebner (1984). The ultrastructure and development of the telotrophic ovary. In: R.C. King and H. Akai (eds) Insect Ultrastructure vol. 2 pp 3-48. Plenum Press, New York

[15]. W.A. Garthe (1970). Development of the female reproductive system and effect of males on oocyte production in Sitona cylindricollis (Coleoptera: Curculionidae). Annals of the Entomological Society of America 63 (2): 367-370

[16]. T.S. Adams (2000). Effect of diet and mating status on ovarian development in predaceous stink bug Perillus bioculatus (Hemiptera: Pentatomidae). Annals of the Entomological Society of America 93 (3): 529-535

[17]. P. Fortes, G. Salvador and F.L. Consoli (2011). Systematics, morphology and physiology: Ovary development and maturation in Nezara viridula (L.) (Hemiptera: Pentatomidae). Neotropical Entomology 40: 89-96. http://dx.doi.org/10.1590/S1519566X2011000100013

[18]. M. Shahid, A. Siddiqui, OMKAR, and G. Mishra (2016). Mating alters the rate of development of ovarioles in the ladybird, Propylea dissecta (Coleoptera: Coccinellidae). European Journal of Entomology. 113: 44-50. doi: 10.14411/eje.2016.005 